\title{
Desenvolvimento de dispositivo assistivo para higiene oral baseado em metodologia de projeto participativo
}

\author{
Development of assistive device for oral hygiene based on participatory \\ design methodology
}

\section{Desarrollo de dispositivo de asistencia para la higiene bucal basado en metodología de diseño participativo}

\section{Luciana Bolzan Agnelli Martinez}

Professora doutora da Universidade Federal de São Carlos, São Carlos, SP, Brasil

E-mail: luagnelli@ufscar.br ORCID: https://orcid.org/0000-0003-0873-9806

\section{Maraísa Alves dos Santos}

Graduada pela Universidade de São Paulo, São Carlos, SP, Brasil

E-mail: maraisalvess@gmail.com ORCID: https://orcid.org/0000-0002-5320-765X

\section{Zilda de Castro Silveira}

Professora doutora da Universidade de São Paulo, São Carlos, SP, Brasil

E-mail: silveira@sc.usp.br ORCID: https://orcid.org/0000-0002-5040-0403

Recebido em 09 de março de 2021

Aprovado em 27 de julho de 2021

Publicado em 31 de agosto de 2021

\section{RESUMO}

A Tecnologia Assistiva apresenta impacto positivo no desempenho ocupacional de pessoas com deficiência, incluindo crianças e adolescentes com paralisia cerebral, com evidências de melhora na independência e inclusão social, em contextos de educação, trabalho, lazer e domicílio. Muitos desafios acompanham o desenvolvimento e a implementação de produtos assistivos, sendo que o envolvimento do usuário final é importante para minimizar o abandono e melhorar a usabilidade e funcionalidade. Este trabalho teve como objetivo o desenvolvimento de um dispositivo assistivo para higiene oral e teste dos protótipos funcionais resultantes junto ao usuário final, a fim de avaliar sua satisfação e propor melhorias a partir de sua opinião. Foi adotada uma metodologia de projeto participativo, denominada Projet8-TA, que apresenta três macroetapas, nas quais há um conjunto de tarefas apoiadas por técnicas de projeto. Para sua aplicação houve parceria entre profissionais da engenharia e da área da saúde e foi selecionada uma adolescente com alterações neuromotoras decorrentes de paralisia cerebral, que participou ativamente do desenvolvimento e teste dos protótipos. A satisfação da participante foi avaliada através da versão brasileira do instrumento padronizado Quebec User Evaluation of Satisfacion with Assistive Tecnology (B-QUEST - 2.0). Os resultados demonstraram potencialidade da metodologia utilizada em relação a: tempo de projeto reduzido, maior interação entre equipe e usuário e maior assertividade na solução técnica do dispositivo assistivo. Além disso, a participação do usuário final foi fundamental para o andamento do projeto e para o desenvolvimento da versão final do dispositivo assistivo. 
http://dx.doi.org/10.5902/1984686X64660

Palavras-chave: Tecnologia Assistiva; Pessoas com Deficiência; Projeto focado em customização.

\section{ABSTRACT}

Assistive Technology has a positive impact on the occupational performance of people with disabilities, including children and adolescents with cerebral palsy, with evidence of improved independence and social inclusion, in contexts of education, work, leisure and home. Many challenges accompany the development and implementation of assistive products, and user participation is important to minimize abandonment and improve usability and functionality. This work aimed to develop an assistive device for oral hygiene and test the resulting functional prototypes with the end user, to assess their satisfaction and propose improvements based on their opinion. A participatory project methodology called Projet8-TA was adopted, which presents three macro steps, in which there is a set of tasks supported by design techniques. For its application, there was a partnership between engineering and healthcare professionals, and a teenager with neuromotor disorders resulting from cerebral palsy was selected, who actively participated in the developing and testing prototypes. Participant's satisfaction was assessed through the Brazilian version of the standardized instrument Quebec User Evaluation of Satisfaction with Assistive Technology (B-QUEST 2.0). The results showed the potential of the methodology used in relation to: reduced project time, greater interaction between team and user and greater assertiveness in the technical solution of the assistive device. Furthermore, the participation of the end user was fundamental for the project's progress and for the development of the final version of the assistive device.

Keywords: Assistive Technology; Disabled people; Design for customization.

\section{RESUMEN}

La Tecnología Asistencial tiene un impacto positivo en el desempeño ocupacional de las personas con discapacidad, incluidos los niños y adolescentes con parálisis cerebral, con evidencia de una mayor independencia e inclusión social en los contextos educativo, laboral, de ocio y del hogar. Muchos desafíos acompañan al desarrollo y la implementación de productos de asistencia, y la participación del usuario final es importante para minimizar el abandono y mejorar la usabilidad y la funcionalidad. Este trabajo tuvo como objetivo desarrollar un dispositivo de asistencia para higiene bucal y probar los prototipos funcionales resultantes con el usuario final, con el fin de evaluar su satisfacción y proponer mejoras en función de su opinión. Se adoptó una metodología de proyectos participativos, denominada Projet8-TA, que presenta tres macro etapas, en las que hay un conjunto de tareas apoyadas en técnicas de proyectos. Para su aplicación, se contó con una alianza entre ingenieros y profesionales de la salud y se seleccionó a un adolescente con trastornos neuromotores derivados de parálisis cerebral, quien participó activamente en desarrollo y prueba del prototipo. La satisfacción de los participantes se evaluó utilizando la versión brasileña del instrumento estandarizado Quebec User Evaluation of Satisfaction with Assistive Technology (B-QUEST - 2.0). Los resultados mostraron el potencial de la metodología utilizada con relación a: reducción del tiempo del proyecto, mayor interacción 
http://dx.doi.org/10.5902/1984686X64660

entre equipo y usuario y mayor asertividad en la solución técnica del dispositivo de asistencia. Además, la participación del usuario final fue fundamental para el avance del proyecto y para el desarrollo de la versión final del dispositivo de asistencia.

Palabras clave: Tecnología de Asistencia; Personas con Discapacidad; Proyecto enfocado a la personalización.

\section{Introdução}

Nos últimos 20 anos, com o avanço tecnológico global, a contribuição da Tecnologia Assistiva (TA) na vida das pessoas tem se tornado mais clara e evidente em muitos países. Sua aplicação, quando apropriada, proporciona um desempenho ocupacional significativo, em diferentes atividades e contextos, favorecendo a independência (BOISSELLE; GRAJO, 2018). Há evidências de benefícios físicos, psicológicos e econômicos decorrentes do uso de Dispositivos Assistivos (DA) influenciando na qualidade de vida, na inclusão social e na redução de custos com ações e/ou profissionais de cuidado (SQUIRES e MORRISON, 2019). Além disso, pode proporcionar melhor participação nos contextos da educação e mercado de trabalho (OMS, 2017).

A Organização Mundial da Saúde (OMS), em sua iniciativa voltada para Pesquisa, Inovação e Educação em Tecnologia Assistiva (GREAT), define "tecnologia assistiva" como um conceito abrangente, que se refere à aplicação de conhecimentos direcionados para a manutenção ou melhora do funcionamento e da independência de um indivíduo, incluindo produtos, sistemas e serviços (SMITH et al, 2018). A expressão "produto assistivo" está mais focada nos próprios dispositivos, equipamentos, instrumentos e software.

No Brasil, a expressão Tecnologia Assistiva foi oficializada pelo Comitê de Ajudas Técnicas (CAT), dirigido pela Coordenadoria Nacional para Integração da Pessoa com Deficiência (CORDE), e refere-se a uma área de conhecimento, de característica multidisciplinar, composta por produtos, recursos, estratégias, práticas, processos, métodos e serviços, com o objetivo de promover a funcionalidade e a participação de pessoas com deficiência, mobilidade reduzida ou idosas, visando à autonomia, independência, qualidade de vida e inclusão social (ITS Brasil, 2008).

Dentre as pessoas com deficiência, a literatura aponta que recursos de tecnologia assistiva apresentam impacto positivo na vida de crianças com paralisia cerebral, não apenas para facilitar a acessibilidade sociodigital nas escolas (ITS Brasil, 2008), mas também para: o desenvolvimento global (ROCHA; DELIBERATO, 2012); movimentação 
e comunicação (COWAN; KHAN, 2005; MANZINI; ASSIS; MARTINEZ, 2013); ganho de independência em atividades da vida diária (OSTENSJO; CARLBERG; VOLLESTAD, 2005; LINO et al, 2020); melhor posicionamento durante as atividades (BRACCIALLI et al, 2008; OLIVEIRA; BRACCIALLI, 2008); e para a inclusão escolar de forma ampliada (ITS Brasil, 2008; PELOSI; NUNES, 2009; ALVES; MATSUKURA, 2012).

$\mathrm{Na}$ escola, os recursos podem ser favoráveis para as tarefas em sala de aula e para outros ambientes que a criança participa (ALVES; MATSUKURA, 2011), tais como banheiro, lanche, recreio, transporte e transições, visto que uma inclusão escolar efetiva requer a participação ativa da criança com paralisia cerebral em diversas atividades funcionais que dão suporte para o desenvolvimento de competências pedagógicas e sociais (SILVA et al, 2004).

De acordo com os princípios da Classificação Internacional de Funcionalidade, Incapacidade e Saúde (OMS/CIF, 2003), modificações ambientais e recursos de tecnologia assistiva devem promover a participação plena nas diferentes atividades da vida. Por outro lado, tecnologias inadequadas podem representar barreiras à participação e levar ao abandono, cujos fatores relacionados incluem: falha dos provedores em considerar as opiniões do consumidor; dificuldade de aquisição do dispositivo; baixo desempenho funcional; mudanças nas necessidades e/ou prioridades do consumidor (GRAY; COOK, 2017). Ao pesquisarem diferentes tipos de dispositivos assistivos, Riemer-Reiss e Wacker (2000) encontraram uma taxa de abandono de 32,4\% e ressaltam que o envolvimento do consumidor no processo de desenvolvimento está diretamente associado à continuidade do uso. Dessa forma, muitos desafios acompanham as fases envolvidas no processo de implementação em Tecnologia Assistiva, incluindo o desenvolvimento de produtos, para o qual se recomenda uma abordagem interdisciplinar (COOK; POLGAR, 2008).

Ao investigarem as metodologias utilizadas no desenvolvimento de produtos assistivos, Maia e Freitas (2014) identificaram problemas relacionados com 0 desenvolvimento assistemático de projeto, a desconsideração da importância de parâmetros estéticos para o usuário e o não envolvimento da família no processo de avaliação. Além disso, foram identificadas lacunas em etapas importantes, tais como geração de ideias (10\%), teste (20\%) e treinamento (20\%).

Alguns trabalhos têm sido realizados com ênfase no uso de técnicas de projeto durante as fases informacional e conceitual do projeto de desenvolvimento em TA, tais 
http://dx.doi.org/10.5902/1984686X64660

como Cavalcanti (2016) e Barbosa (2016), que desenvolveram conceito e protótipo funcional de um dispositivo assistivo para pessoas com tetraplegia; Kaneko (2018), que desenvolveu um dispositivo para a escrita; e Loureiro (2019), que apresentou uma solução inovativa para a área da alimentação. Nesses trabalhos, verifica-se a busca por uma interface entre as decisões técnicas da engenharia e os requisitos do usuário, principalmente através da inserção da experiência de profissionais da saúde no desenvolvimento do conceito. Bersch (2017) defende que o próprio usuário e seus familiares devem ser capacitados pela equipe para que se tornem aptos a participarem do desenvolvimento de um novo dispositivo/serviço, desde a "definição do problema", em que devem expor as dificuldades a serem superadas, até a participação ativa no "desenvolvimento" e "teste", compartilhando suas experiências para a tomada das melhores decisões.

Diante das perspectivas atuais da área de Tecnologia Assistiva, observam-se tendências e oportunidades para o projeto participativo (SANTOS; SILVEIRA, 2020), em que os usuários podem ser considerados apropriadores criativos, pensadores ou mesmo coprojetistas no processo de desenvolvimento de produtos (OSTUZZI et al., 2015). Isto favorece a usabilidade do dispositivo assistivo e diminui a possibilidade de rejeição, a fim de alcançar níveis de personalização, ao invés de apenas customização. O coprojeto utiliza técnicas e abordagens iterativas e coloca os usuários em destaque, tornando-os projetistas na medida em que sugerem melhorias no projeto com base em suas experiências e preferências (DE COUVREUR; GOOSSENS, 2011; PORTNOVA et al., 2018).

Santos (2020) propôs a estruturação de uma metodologia de projeto, da perspectiva da engenharia e no contexto da Tecnologia Assistiva. A metodologia, denominada projet8TA ou, em inglês, AT-8esign (AT-8d), é marcada por um caráter iterativo e dinâmico e visa a aplicação de ferramentas e técnicas da engenharia nos projetos de dispositivos assistivos, com abordagem centrada no usuário.

Nesse contexto, o presente estudo teve como objetivo principal o desenvolvimento de um dispositivo assistivo para a higiene oral, considerando as necessidades de usuários com alterações neuromotoras, pautado no conceito de "Design for Assistive Tecnology", por meio da aplicação da metodologia "Projet8-TA". Além disso, o trabalho teve a finalidade de testar os protótipos funcionais resultantes junto ao usuário final, e considerar sua opinião para aprimorar o recurso, através da avaliação de satisfação. 


\section{Materiais e Métodos}

A metodologia denominada projet8-TA (p8-TA), proposta por Santos (2020), expandida e readequada com base em Pahl et al. (2007) e Ullman (2010), sintetiza as experiências adquiridas em trabalhos multidisciplinares realizados por Souza (2016), Barbosa (2016), Kaneko (2018), Loureiro (2019), Martinez (2020) e Cavalcanti et al (2020), com foco em dispositivos assistivos.

A metodologia é dividida em três fases principais, como pode ser visto na Figura 1: (1) Domínio Transversal de Projeto (DTP); (2) Espiral de concepção; (3) Avaliação e refinamento. $\mathrm{O}$ nome adotado é uma referência à palavra projeto (em inglês: design), à sigla para Tecnologia Assistiva (TA) e ao caráter iterativo e dinâmico do método, cujo fluxo das informações entre as partes envolvidas e entre as fases (sobretudo 2 e 3) não é propriamente sequencial, mas cíclico. Enquanto a primeira fase tem um caráter preparatório, as duas últimas representam o núcleo criativo do processo. Cada uma delas, por sua vez, se subdivide em quatro etapas principais.

Figura 1 - Metodologia Projet8-TA (fases e tarefas)
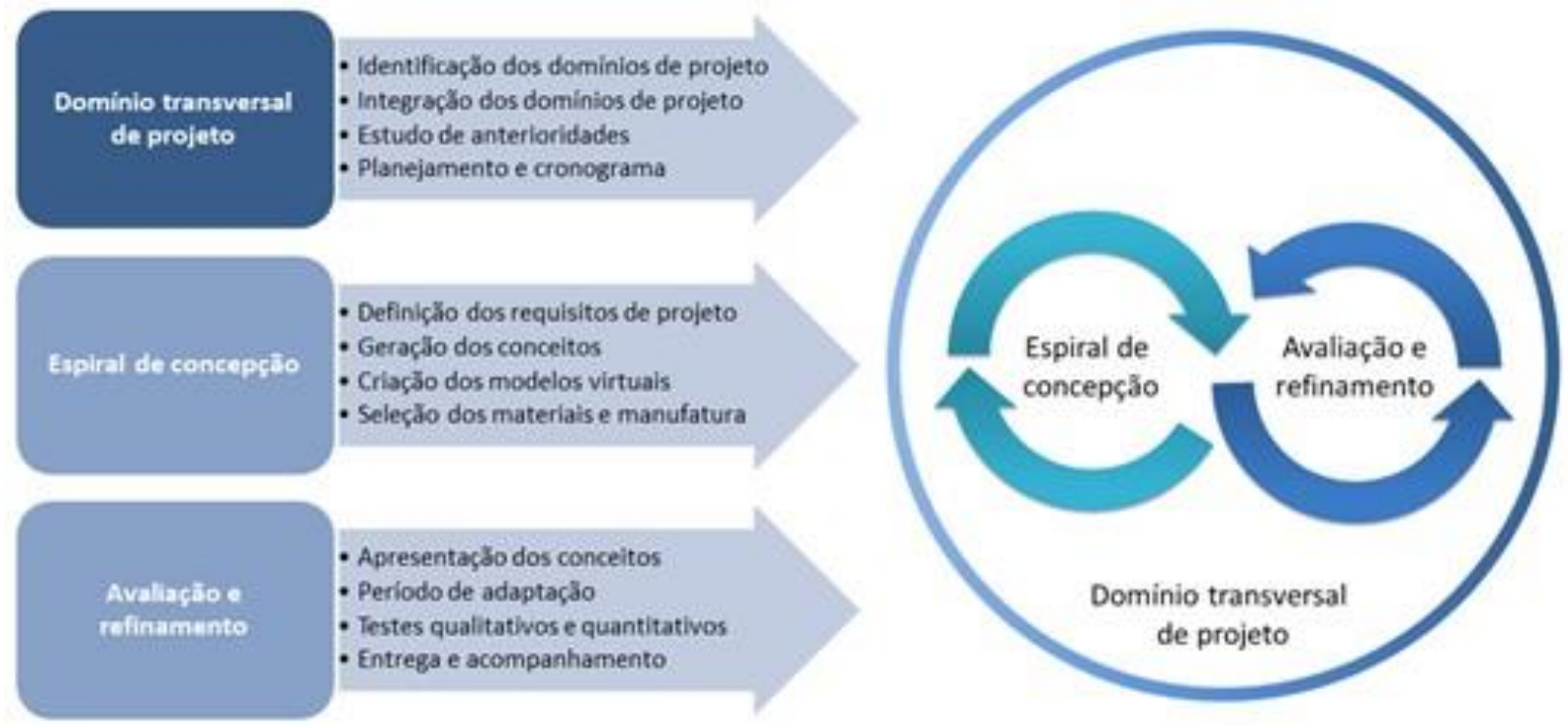

Fonte: Santos e Silveira (2020).

A primeira fase - Domínio Transversal de Projeto (DTP) - visa à criação do arcabouço fundamental de conhecimentos, habilidades e experiências para $\mathrm{O}$ desenvolvimento do projeto, a partir da integração de todos os domínios de interesse. A segunda fase - Espiral de Concepção - é o núcleo mais criativo do processo, na qual são elaborados e aperfeiçoados, com o auxílio de ferramentas e técnicas de projeto, os 
http://dx.doi.org/10.5902/1984686X64660

conceitos e soluções sobre o DA e na qual são fabricados, via manufatura aditiva, os mock-ups, protótipos e produtos. Por fim, a terceira fase - Avaliação e refinamento - tem por objetivo avaliar, junto ao usuário e demais membros do DTP, a satisfação em relação ao dispositivo, bem como sua funcionalidade e eficácia, de maneira a realimentar a fase anterior em busca do aperfeiçoamento do projeto.

\section{Aplicação da metodologia Projet8-TA}

\section{Primeira Fase - Domínio Transversal do Projeto}

Inicialmente foram feitas a "Identificação e a Integração dos Domínios de Projeto", por meio de coleta de dados para embasar o entendimento dos impactos que as alterações neuromotoras podem gerar no desempenho funcional de crianças e adolescentes em diversas atividades cotidianas, especificamente na higiene oral. Para isso, houve coleta e refinamento dos dados e o estabelecimento do perfil do usuário/nicho que poderia utilizar o dispositivo assistivo, para nortear a fase conceitual do projeto. Os dados foram coletados junto a profissionais da área de saúde de uma cidade do interior do estado de São Paulo, em uma Unidade Saúde Escola. Além da engenharia, a equipe foi composta por dois terapeutas ocupacionais, dois fisioterapeutas e uma psicopedagoga, que responderam a um questionário aberto sobre a atividade da higiene oral e as principais adaptações que normalmente são necessárias para facilitar o desempenho funcional nessa situação. Além de identificar as dificuldades dessa atividade para pessoas com deficiência e o público-alvo para equipamentos facilitadores, houve questões sobre as opções do mercado e a facilidade de acesso. Após o levantamento de informações acerca da execução da atividade e das várias tarefas e etapas que a compõem, assim como dos tipos de dispositivos de tecnologia assistiva que poderiam ser propostos, foi selecionada a tarefa da escovação dos dentes como objetivo principal para o dispositivo a ser desenvolvido. Estabeleceu-se como público-alvo principal pessoas com comprometimento nos membros superiores e com dificuldade para a preensão da escova de dente durante a higiene oral, como, por exemplo, pessoas com alterações neurológicas decorrentes de Paralisia Cerebral.

Por meio de sessões de Brainstorming, um novo questionário foi elaborado com perguntas objetivas, em que profissionais da área da saúde atribuíram notas para vários requisitos que o dispositivo assistivo poderia apresentar. Foram estabelecidas três possibilidades de pontuação, baseadas em Clausing (1994): 9 (Muito importante), 3 
(Importante) e 1 (Pouco importante). A partir desse resultado e da parceria entre engenharia e terapia ocupacional, juntamente com as pesquisas iniciais sobre soluções comerciais, foi possível classificar os requisitos selecionados, quanto ao grau de importância, a saber: Fácil limpeza (9); Ser confortável (9); Não agredir a pele (9); Resistir a impacto (9); Não agredir a mucosa (9); Sensação térmica agradável (3) e Ser compacto (1).

Ainda na primeira fase, conforme está previsto na metodologia Projet8-TA, foi realizado um "Estudo de anterioridades" de soluções conceituais para higiene oral e escovação dos dentes, por meio das bases tecnológicas Google Patents e Espacenet, estabelecendo-se os seguintes termos para a busca: "toothbrush", "toothbrush adapted", "orthosis" e "orthosis for hands". Foram encontradas três patentes e um produto comercial específico para a higiene oral, conforme se segue:

- Patente de invenção de uma escova de dente capaz de executar confortavelmente a ação de escovação, massageando as gengivas e dentes, além de retirar os alimentos entre os dentes, especialmente os molares (SUNG-SHAN, 1984);

- Patente de uma órtese ativa de membros superiores, para auxiliar o indivíduo a manter objetos e movê-los (GELÁNYI, 2018);

- Patente de uma escova de dente com cabo curvo e alça achatada transversalmente, moldada em planos laterais ortogonais e longitudinalmente torcida para proporcionar uma melhor aderência. A alça curva facilita a escovação das superfícies linguais e/ou dos dentes (DIETRICH,1977);

- Dispositivo comercial denominado Oral Suction Evacuator Brush $\circledast$, da empresa Plak-Vac, desenvolvido para pessoas com dificuldade para engolir e expectorar, ou que não podem realizar cuidados orais de rotina.

\section{Segunda Fase - Espiral de concepção}

Essa fase foi norteada pelas características extraídas da lista de Requisitos Técnicos da matriz da qualidade (comumente referida como "casa da qualidade"), que é a primeira matriz do Método Quality Function Deployment - QFD (CHENG; MELO FILHO, 2007), cujo resultado em relação ao grau de importância é apresentado na Figura 2. 
http://dx.doi.org/10.5902/1984686X64660

Figura 2 - Matriz de correlação: "Casa da Qualidade"

\begin{tabular}{|c|c|c|c|c|c|c|c|c|c|c|c|c|c|c|c|}
\hline & coluna \# & 1 & 2 & 3 & 4 & 5 & 6 & 7 & 8 & 9 & & & & & \\
\hline & 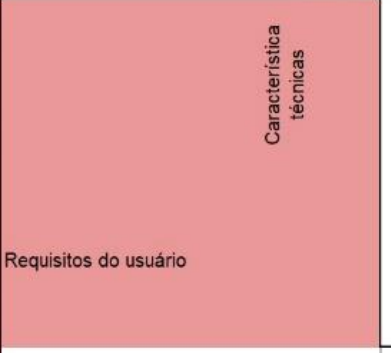 & 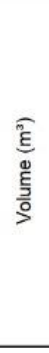 & 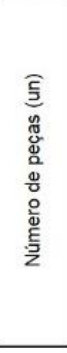 & 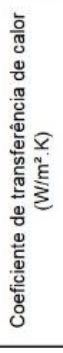 & 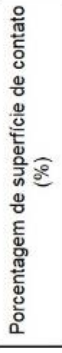 & 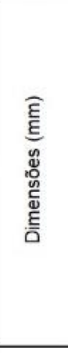 & 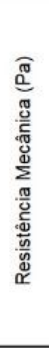 & 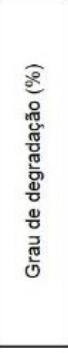 & 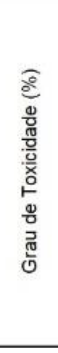 & 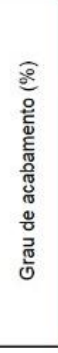 & 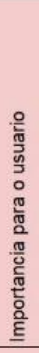 & 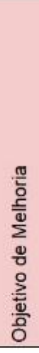 & 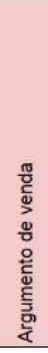 & 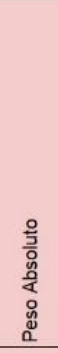 & 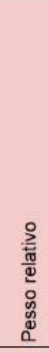 \\
\hline 1 & Ser compacta & 0 & & & & & & & & & 1 & 1 & 1 & 1 & $2 \%$ \\
\hline 2 & Fácil limpeza & & ○ & & & & & 0 & & $\nabla$ & 9 & 1 & 1,5 & 13,5 & $23 \%$ \\
\hline 3 & Sensação térmica & & & - & & & & & & & 3 & 1 & 1 & 3 & $5 \%$ \\
\hline 4 & Anatômico (conforto) & & & & 0 & ○ & & & & & 9 & 1 & 1,5 & 13,5 & $23 \%$ \\
\hline 5 & Resistência ao impacto & & & & & 0 & 0 & 0 & & & 9 & 1 & 1 & 9 & $16 \%$ \\
\hline 6 & Não agredir a pele & & & & & & & - & 0 & & 9 & 1 & 1 & 9 & $16 \%$ \\
\hline 7 & Não agredir a mocosa & & & & & & & $\mathrm{O}$ & - & & 9 & 1 & 1 & 9 & $16 \%$ \\
\hline & $\begin{array}{r}\text { Peso Absoluto } \\
\text { Peso Relativo }\end{array}$ & $\begin{array}{c}9 \\
1 \% \\
\end{array}$ & $\begin{array}{c}121,5 \\
18 \%\end{array}$ & $\begin{array}{l}27 \\
4 \% \\
\end{array}$ & $\begin{array}{l}40,5 \\
6 \% \\
\end{array}$ & $\begin{array}{c}148,5 \\
22 \% \\
\end{array}$ & $\begin{array}{l}37 \\
5 \% \\
\end{array}$ & $\begin{array}{r}75,5 \\
26 \% \\
\end{array}$ & $\begin{array}{c}108 \\
16 \% \\
\end{array}$ & $\begin{array}{l}13,5 \\
2 \% \\
\end{array}$ & & & & & \\
\hline
\end{tabular}

Fonte: Elaborada pelos autores (2021).

A partir da conversão dos requisitos do usuário em características técnicas, foi possível construir a matriz de correlação entre eles, sendo que foram adotados quatro indicadores para essa relação, com base em Clausing (1994), representados por números e símbolos: 0 (inexistente), 1 ou $\Delta$ (fraca), 3 ou o (média) e 9 ou $\bullet$ (forte).

Observa-se que alguns requisitos do usuário possuem correspondência direta para características técnicas, como é o caso de "ser compacta", convertida para "volume", e "sensação térmica", cuja característica selecionada foi "coeficiente de transferência de calor". Outros apresentam mais de uma correlação com características técnicas, como "fácil limpeza", que se relaciona com "número de peças" (quanto menos peças, mais fácil de limpar), "grau de degradação" e "grau de acabamento", já que a forma como será realizada a limpeza e a rugosidade do material influenciam tal requisito. Outro exemplo é o requisito "Anatômico", que está relacionado com "dimensões", pois o tamanho influencia no conforto, e com "porcentagem de superfície de contato", que também interfere diretamente no requisito. Em relação à "resistência ao impacto", fez-se a conversão direta para "resistência mecânica", porém percebeu-se também uma relação média com "dimensões" e com o "grau de degradação", pois sua área e a degradação do material podem influenciar na resistência ao impacto. Por fim, "não agredir a pele" e "não agredir a mucosa" relaciona-se com "grau de toxicidade" e "grau de degradação", com pesos diferentes. 


\section{Geração de conceitos}

Essa tarefa consiste em realizar atividades de convergência e divergência, com auxílio de ferramentas de projeto que promovam a criatividade por meio de abordagens intuitivas e/ou estruturadas. Neste estudo foram utilizadas sistematicamente:

- A metodologia TRIZ (princípio de soluções inventivas), que auxiliou na resolução das contradições técnicas;

- A técnica funcional MEI (Matéria-Energia-Sinal), para transformar o problema em estrutura semântica (verbo + substantivo) e para auxiliar no processo de divergência do problema;

- A matriz morfológica, para escolha da combinação mais viável;

- A técnica FMEA (Failure Mode Effects and Analysis), para a escolha de soluções técnicas com menor probabilidade de falha e desconforto.

A metodologia TRIZ inicia-se pela análise comparativa, aos pares, entre as características técnicas extraídas a partir dos requisitos do usuário. Essas comparações compõem o "telhado" da "casa da qualidade" e podem ser abordadas, em termos de projeto de engenharia, como: relações 'construtivas' (representadas por "+") ou 'destrutivas' (representadas por "-"). A Figura 3 apresenta as principais contradições técnicas identificadas pela equipe de projeto.

Figura 3 - "Telhado" da "Casa da Qualidade": contradições técnicas

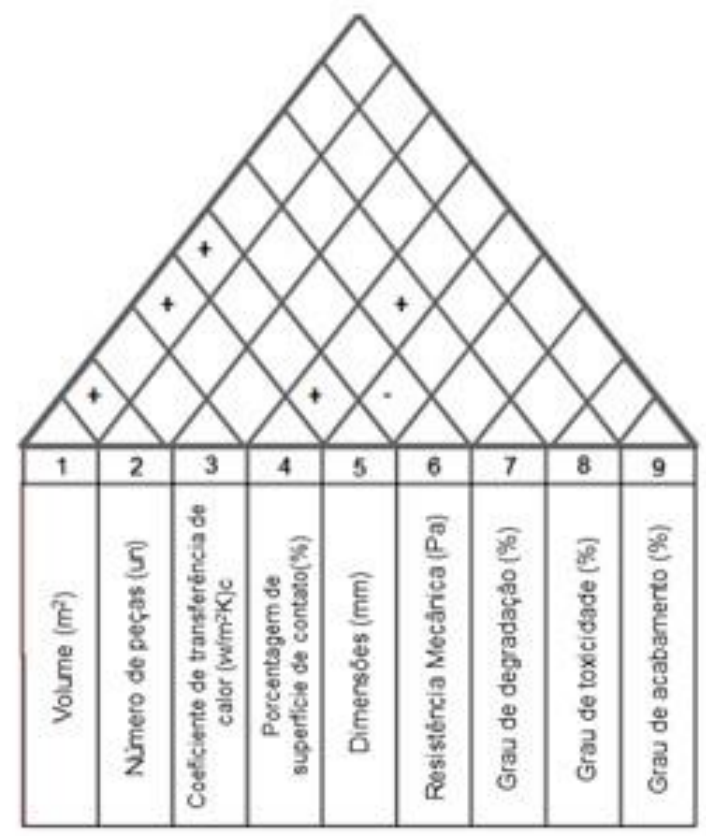

Fonte: Elaborada pelos autores (2021). 
http://dx.doi.org/10.5902/1984686X64660

Analisando-se as comparações, pode-se estabelecer as seguintes relações técnicas:

- Volume $\left(\mathrm{m}^{3}\right)$ e número de peças (un): a relação é proporcional, ou seja, o aumento do número de peças faz com que o volume do produto final aumente (caso seja o mesmo material);

- Volume $\left(\mathrm{m}^{3}\right)$ e porcentagem de superfície de contato (\%): como área e volume são diretamente proporcionais, sua relação também é direta (ou "construtiva");

- Volume $\left(\mathrm{m}^{3}\right)$ e dimensões $(\mathrm{mm})$ : como volume e dimensões são diretamente proporcionais, sua relação também é direta;

- Porcentagem de superfície de contato (\%) e dimensões (mm): como área e dimensões são diretamente proporcionais, sua relação também é direta;

- Porcentagem de superfície de contato (\%) e grau de degradação (\%): o material tende a se degradar mais rapidamente quando em contato com a pele e a mucosa. Por isso, sua relação é "construtiva";

- Dimensões $(\mathrm{mm})$ e resistência mecânica $(\mathrm{Pa})$ : esta relação foi considerada inversamente proporcional e, portanto, "destrutiva".

A metodologia TRIZ estabelece duas matrizes, com 40 princípios inventivos e 39 parâmetros de engenharia, extraídos de um levantamento sistemático feito por Altshuller (2007), em que são conjugadas possíveis soluções para um problema genérico e se extrai uma solução específica. Duas contradições foram escolhidas em função do grau de importância das características técnicas: "dimensões x resistência mecânica" e "porcentagem de superfície de contato x grau de degradação". Para a segunda contradição, foi utilizado o princípio inventivo 35, que sugere mudança de parâmetros e propriedades.

Para os desdobramentos das funções secundárias, conforme se observa no Diagrama MEI (Figura 4), a função básica de projeto foi definida como "Auxiliar a atividade de higiene oral", através da escovação dos dentes, tendo como "entradas": Matéria (dispositivo, mão, escova e pasta de dente), Energia (Muscular) e Informação (Verificar ajuste inicial). Como "saídas" tem-se: Matéria (Dispositivo e mão), Energia (Muscular, cinética e térmica) e Informação (Verificar ajuste final). 
http://dx.doi.org/10.5902/1984686X64660

Figura 4 - Diagrama MEI desdobrado

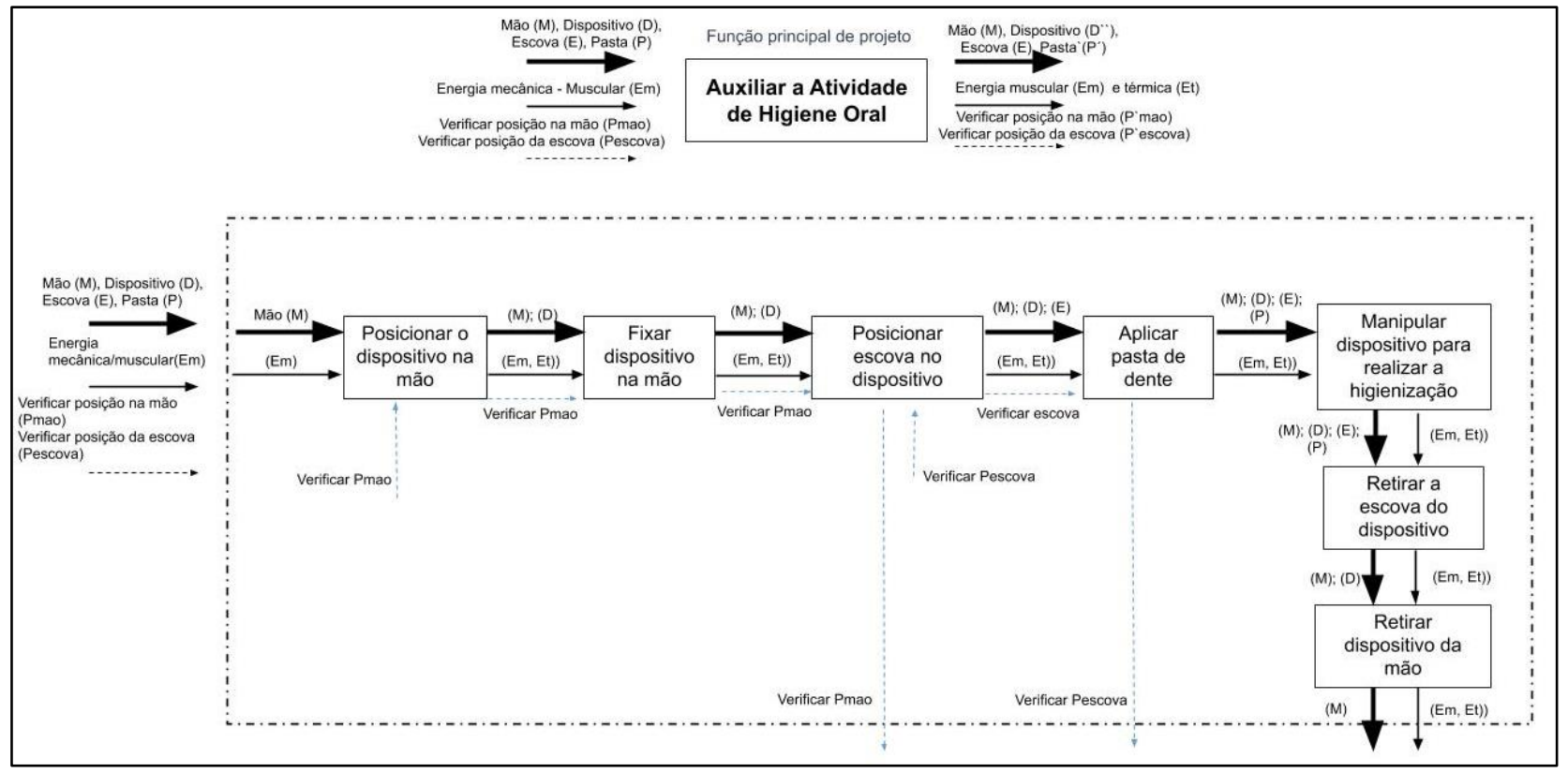

Fonte: Elaborada pelos autores (2021).

A escolha das soluções construtivas para os parâmetros técnicos extraídos da análise funcional (MEI) foi feita através da Análise Morfológica (PAHL. et al, 2007), cuja aplicação para o dispositivo assistivo desenvolvido neste trabalho apresenta-se no Quadro 1.

Quadro 1 - Análise morfológica: solução construtiva do dispositivo assistivo para higiene oral

\begin{tabular}{|c|c|c|c|c|c|}
\hline PARÂMETROS & \multicolumn{5}{|c|}{ SOLUÇÕES } \\
\hline Material & $\begin{array}{l}\text { Polímero } \\
\text { termo } \\
\text { moldável }\end{array}$ & Elastômero & Neoprene & Algodão & - \\
\hline Formato & Luva & $\begin{array}{l}\text { Luva sem } \\
\text { dedos }\end{array}$ & Tala & Fita_com ab & a polegar \\
\hline Escova & \multicolumn{2}{|c|}{ Conjunto com órtese } & \multicolumn{2}{|c|}{ Modelo próprio } & $\begin{array}{l}\text { ualquer } \\
\text { scova }\end{array}$ \\
\hline $\begin{array}{c}\text { Fixação escova } \\
\text { (restrição movimento no eixo x) }\end{array}$ & $\begin{array}{l}\text { Dispositivo } \\
\text { acoplado }\end{array}$ & \multicolumn{4}{|c|}{ Costura no canal _..... Zíper } \\
\hline $\begin{array}{c}\text { Fixação escova } \\
\text { (restrição movimento no eixo y) }\end{array}$ & \multicolumn{2}{|c|}{ Cola } & \multicolumn{3}{|c|}{ Silicone } \\
\hline Local para acoplar escova & Palma da mãc & \multicolumn{2}{|c|}{ Dorso da mão } & \multicolumn{2}{|c|}{ Diferentes posições } \\
\hline Ajuste na mão & \multicolumn{2}{|c|}{ Único } & \multicolumn{2}{|c|}{ __-Reguúlável } & - \\
\hline Dispositivo para fechar & Velcro & $\begin{array}{l}\text { - - Botãó- } \\
\text { - simples }\end{array}$ & Zíper & $\begin{array}{l}\text { Botão de } \\
\text { pressão }\end{array}$ & - \\
\hline Cor & Branco & Preto & - Amarela. & Vermelho & Azul \\
\hline Dimensões(cm) & $\begin{array}{l}\text { Feito sob } \\
\text { medida }\end{array}$ & $20 \times 5$ & $--15 \times 4$ & $21 \times 5$ & - \\
\hline
\end{tabular}

Fonte: Elaborado pelos autores (2021). 
http://dx.doi.org/10.5902/1984686X64660

Utilizando-se como referência os graus de importância obtidos na "Casa da Qualidade" (Figura 2), para cada linha são inseridos parâmetros/soluções que possam ser discutidos pela equipe multidisciplinar. Verifica-se que o primeiro parâmetro estabelecido para este trabalho foi a escolha do "material", selecionado a partir do requisito do usuário "fácil de limpar", que foi desdobrado fortemente como característica técnica "número de peças" e que apresentou correlações fracas com outras características, como grau de degradação e acabamento. Diante das possíveis soluções previstas para o material, por exemplo, foi escolhido o Neoprene ${ }^{\circledR}$, por ter baixa densidade, alto módulo de elasticidade e estabilidade em condições de alta umidade.

Dessa forma, a partir de uma combinação de soluções, são extraídas, por algum critério, uma ou duas soluções potencialmente viáveis. Nesse trabalho, para essa seleção foi utilizado o FMEA conceitual (Quadro 2), garantindo que a "trajetória" de escolhas do Quadro 1 fosse viável. Foram analisadas três etapas do processo, que provocaram uma discussão minuciosa, devido sua grande importância para o conforto do consumidor e funcionamento do produto.

Quadro 2 - Critério FMEA para auxiliar na escolha da melhor solução no quadro morfológico

\begin{tabular}{|c|c|c|c|c|c|}
\hline PROCESSO & $\begin{array}{l}\text { PRINCIPAIS } \\
\text { ENTRADAS DO } \\
\text { PROCESSO }\end{array}$ & $\begin{array}{l}\text { MODO DE } \\
\text { FALHA } \\
\text { POTENCIAL }\end{array}$ & $\begin{array}{l}\text { EFEITOS DAS } \\
\text { FALHAS } \\
\text { POTENCIAIS }\end{array}$ & $\begin{array}{l}\text { CAUSAS } \\
\text { POTENCIAIS }\end{array}$ & $\begin{array}{c}\text { AÇÕES } \\
\text { RECOMENDADAS }\end{array}$ \\
\hline \multirow{2}{*}{$\begin{array}{l}\text { Confecção } \\
\text { do } \\
\text { dispositivo }\end{array}$} & \multirow[b]{2}{*}{$\begin{array}{l}\text { Escolha do } \\
\text { material }\end{array}$} & $\begin{array}{c}\text { Dispositivo duro, não } \\
\text { anatômico ou } \\
\text { maleável }\end{array}$ & $\begin{array}{l}\text { Ser desconfortável; } \\
\text { machucar a mão }\end{array}$ & $\begin{array}{l}\text { Material duro, com } \\
\text { rebarbas ou tamanho } \\
\text { não adequado }\end{array}$ & $\begin{array}{l}\text { Escolher material que } \\
\text { acompanhe o formato } \\
\text { da mão e seja elástico }\end{array}$ \\
\hline & & Difícil de limpar & $\begin{array}{l}\text { Mau cheiro, } \\
\text { dispositivo sujo }\end{array}$ & $\begin{array}{c}\text { Material que } \\
\text { apresente muitos } \\
\text { cuidados para limpeza }\end{array}$ & $\begin{array}{c}\text { Material fácil de limpar, já } \\
\text { utilizado em atividades } \\
\text { com exposição à umidade } \\
\text { e água }\end{array}$ \\
\hline \multirow{3}{*}{$\begin{array}{l}\text { Local de } \\
\text { encaixe e } \\
\text { fixação da } \\
\text { escova }\end{array}$} & \multirow{3}{*}{$\begin{array}{l}\text { Formato } \\
\text { específico }\end{array}$} & \multirow{3}{*}{$\begin{array}{l}\text { Não encontrar } \\
\text { uma escova que } \\
\text { seja compatível } \\
\text { com o formato } \\
\text { projetado }\end{array}$} & $\begin{array}{l}\text { Cliente comprar } \\
\text { dispositivo e não } \\
\text { conseguir utilizar } \\
\text { por não encontrar } \\
\text { escova que } \\
\text { encaixe }\end{array}$ & \multirow{3}{*}{$\begin{array}{c}\text { Formato específico } \\
\text { para encaixar a } \\
\text { escova }\end{array}$} & \multirow{3}{*}{$\begin{array}{l}\text { Uso de qualquer tipo } \\
\text { de escova, não usar } \\
\text { um modelo próprio }\end{array}$} \\
\hline & & & $\begin{array}{c}\text { Modelo de escova } \\
\text { escolhido ser de preço } \\
\text { elevado }\end{array}$ & & \\
\hline & & & $\begin{array}{c}\text { Cliente não } \\
\text { comprar por não } \\
\text { conhecer o modelo } \\
\text { de escova } \\
\text { requisitado }\end{array}$ & & \\
\hline \multirow{2}{*}{$\begin{array}{l}\text { Colocar } \\
\text { escova no } \\
\text { dispositivo }\end{array}$} & \multirow{2}{*}{$\begin{array}{c}\text { Fixação da } \\
\text { escova }\end{array}$} & $\begin{array}{l}\text { Movimentação da } \\
\text { escova no eixo X }\end{array}$ & \multirow{2}{*}{$\begin{array}{l}\text { Dificuldade na } \\
\text { realização da } \\
\text { escovação }\end{array}$} & $\begin{array}{c}\text { Não fixação adequada } \\
\text { da escova na órtese }\end{array}$ & $\begin{array}{c}\text { Limitação de um canal } \\
\text { para posicionar a } \\
\text { escova com uso de } \\
\text { costura }\end{array}$ \\
\hline & & $\begin{array}{l}\text { Movimentação da } \\
\text { escova no eixo Y }\end{array}$ & & $\begin{array}{c}\text { Extremidades da } \\
\text { escova livres } \\
\text { possibilitando seu } \\
\text { movimento no eixo Y }\end{array}$ & $\begin{array}{c}\text { Aplicação de um } \\
\text { dispositivo no furo } \\
\text { superior e inferior que } \\
\text { impossibilite a escova } \\
\text { escorregar }\end{array}$ \\
\hline
\end{tabular}

Fonte: Elaborado pelos autores (2021). 
Houve uma pesquisa sobre materiais que pudessem contemplar as características ligadas à higiene e que, ao mesmo tempo, possibilitassem a fixação da escova de dente. Conforme se verifica no Quadro 1, foi escolhido o Neoprene $\AA$, que é uma borracha sintética recoberta de malha, com baixa densidade, leve, resistente (baixa deformação), com alto módulo de elasticidade, estabilidade em condições de umidade e proteção térmica (mantém a temperatura), o que corrobora com a ação recomendada para o processo de "confecção do dispositivo" na análise do FMEA (Quadro 2). Sobre o formato, escolheu-se fita com abertura para o polegar, de forma que a adolescente conseguisse colocar sozinha.

Para prover o posicionamento da escova sem movimento relativo, optou-se pela simplicidade da costura artesanal nas laterais do canal em torno da escova, em todas as opções de posicionamento, e restringir seu movimento no eixo $X$. Para que ocorresse essa restrição também no eixo $\mathrm{Y}$, decidiu-se pelo uso de um acoplamento de silicone, que impediria a escova de escorregar.

Através desse estudo sistemático foi então elaborada uma solução conceitual do dispositivo (Figura 5a), em que o modelo geométrico do suporte foi baseado nas dimensões da mão da usuária e nas dimensões de uma escova padrão, sendo gerada a primeira versão da solução, por meio de um protótipo funcional (Figura 5b).

Figura 5 - (a) Desenho técnico e (b) protótipo funcional (primeira versão)

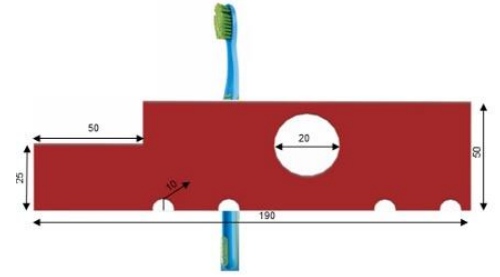

(a)
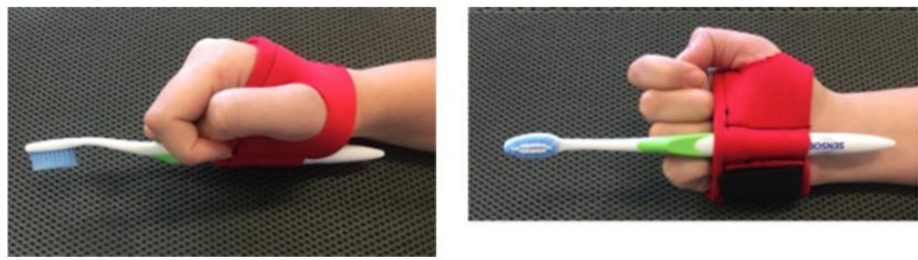

(b)

Fonte: Elaborado pelos autores (2021).

\section{Terceira Fase - Avaliação e Refinamento}

\section{Critérios de Inclusão e seleção do(s) participante(s)}

Foram estabelecidos os seguintes critérios de inclusão: (A) Idade: 8 a 15 anos; (B) Apresentar desempenho funcional prejudicado para a realização da higiene oral; (C) Apresentar dificuldades para manter a escova de dentes em uma das mãos durante a execução da atividade; (D) Não utilizar nenhum dispositivo assistivo para essa atividade e ter interesse em adquirir; (E) Compreender e responder as demandas de interação dos 
pesquisadores, sendo capaz de se comunicar (verbal ou não verbal); $(F)$ Frequentar o serviço de terapia ocupacional, ao menos uma vez por semana, visando a avaliação e o acompanhamento dos procedimentos necessários (antes, durante e após a pesquisa).

Foi selecionada uma adolescente de 15 anos de idade, atendida pela Terapia Ocupacional em uma Unidade Saúde Escola (USE), com alterações neuromotoras decorrentes de paralisia cerebral espástica tetraplégica e classificada como "Grau IV" no Gross Motor Function Classification System for Cerebral Palsy - GMFCS (PALISANO et al, 1997; HIRATUKA; MATSUKYRA; PFEIFER, 2010). Ela foi escolhida e convidada a participar do estudo na medida em que atendeu aos critérios estabelecidos, os quais foram avaliados durante as sessões terapêuticas normalmente realizadas.

A adolescente apresenta alterações na amplitude articular, na coordenação motora global e refinada, com dificuldade para dissociar os movimentos distais dos membros superiores e oscilações ao realizar movimentos precisos, como alcance, preensão e manipulação de objetos. O equilíbrio é prejudicado, de forma que adota poucas posturas independentes, fazendo uso de cadeira de rodas adaptada para se manter sentada de forma adequada e funcional. Estuda em escola regular, com bom desempenho pedagógico e ótimas habilidades sociais e comunicativas. Devido ao tônus elevado, utiliza alguns dispositivos de tecnologia assistiva, tais como: órtese de posicionamento para os membros inferiores, cadeira de rodas motorizada com sistema de adequação postural e computador. É totalmente independente na realização da alimentação e nos cuidados com a aparência. Para demais atividades cotidianas, como a higiene, o vestuário e as transferências da/para a cadeira de rodas, necessita de auxílio parcial ou total. Beneficia-se, portanto, de recursos que auxiliam na estabilidade postural e de adaptações para a fixação ou estabilização de utensílios nas mãos, como por exemplo, os acessórios substituidores de preensão, que podem proporcionar maior independência em diversas situações.

\section{Procedimentos de teste do dispositivo}

Os testes com os protótipos funcionais foram realizados no domicílio da adolescente, para maior facilidade da família e também para que a participante executasse a tarefa no seu contexto natural. Os protótipos desenvolvidos foram testados para que pudessem ser modificados de acordo com as necessidades observadas e relatadas pela participante.

Após cada teste, foi feita a aplicação de um instrumento de avaliação padronizado, elaborado especificamente para avaliar/quantificar a satisfação do usuário com o 
equipamento de tecnologia assistiva, o Quebec User Evaluation of Satisfaction with Assistive Technology, em sua versão brasileira (B-QUEST 2.0). Este instrumento pode auxiliar pesquisadores e profissionais da área nas análises de custo-benefício, custoefetividade e custo-utilidade, tornando possível melhorias técnicas (DEMERS, 2002; CARVALHO; GOIS JÚNIOR; SÁ, 2014). No presente estudo, sua aplicação foi feita por meio de entrevista com a participante, com o objetivo de obter e registrar sua opinião em relação a cada protótipo do dispositivo assistivo para a escovação dos dentes, com a possibilidade de quantificação através da escala de pontuação oferecida pelo instrumento.

O B-QUEST é dividido em duas partes, totalizando 12 itens: oito na primeira parte, que analisa o recurso em si, e quatro na segunda parte, em que se analisa o serviço, sendo que cada item é pontuado pelo usuário final em uma escala de 1 (insatisfeito) a 5 (totalmente satisfeito) (CARVALHO et al., 2014). Este trabalho utilizou somente a primeira parte do instrumento, obtendo-se as notas para cada quesito separadamente, além de uma pontuação geral atribuída ao dispositivo pelo usuário, através da soma e divisão de todas as notas pelo número de itens válidos.

Para a avaliação clínica do dispositivo foi utilizado um experimento de caso único do tipo $A B C$, que subsidiou a Fase Conceitual. A fase inicial $(A)$ consistiu no teste do primeiro protótipo funcional (protótipo da figura 8, com posicionamento da escova na vertical) e as fases de intervenção $(B)$ e $(C)$ ocorreram a partir das interações com a participante, que avaliou e deu sua opinião em relação ao protótipo funcional criado. Na fase (B), portanto, testou-se um protótipo em que a escova foi posicionada em "X", e, na fase (C), o último protótipo funcional, com uma costura mais refinada, a fim de proporcionar maior conforto ao cliente.

$\mathrm{Na}$ fase inicial $(\mathrm{A})$ foi feita uma análise do problema junto ao usuário, para verificar se o dispositivo cumpria com sua função, servindo de parâmetro para as outras fases. Para isso foram adotadas duas etapas:

1) Escovação dos dentes sem uso de dispositivo;

2) Escovação dos dentes com o uso do dispositivo (primeiro protótipo gerado).

Todos os testes foram realizados com a participante sentada e posicionada em sua cadeira de rodas adaptada, equipamento no qual ela permanece para realizar rotineiramente a higiene oral.

Ressalta-se que a pesquisa foi submetida ao Comitê de Ética em Pesquisas (CEP) envolvendo seres humanos, sendo aprovada através do parecer nํㅜ 3.644.276 e Certificado 
http://dx.doi.org/10.5902/1984686X64660

de Apresentação para Apreciação Ética (CAAE) № 12413219.7.0000.5504. A cuidadora principal (mãe) assinou um Termo de Consentimento Livre e Esclarecido (TCLE) e a adolescente assinou um Termo de Assentimento Livre e Esclarecido (TALE).

\section{Resultados}

$\mathrm{Na}$ fase (A), constatou-se grande dificuldade por parte da participante para a realização da tarefa requerida (escovar os dentes), especialmente na etapa 1, sem uso do dispositivo, em que a participante não conseguiu segurar a escova, nem levar à boca, de forma que não foi realizado movimento funcional para sua execução. Na etapa 2, com uso da primeira versão do protótipo, notou-se que a adolescente conseguiu colocar o dispositivo sozinha, acoplar a escova, aproximá-la da boca e realizar alguns movimentos de escovação, apenas do lado direito da boca. Apresentou dificuldade para mudar a posição da escova e não realizou os mesmos movimentos do lado esquerdo. Após a realização da atividade e da primeira avaliação em relação ao uso do dispositivo assistivo para escovar os dentes (Fase A), foi possível estabelecer, a partir da perspectiva do usuário final, três requisitos de prioridade no projeto, a serem adotados nas fases (B) e (C): durabilidade, facilidade de ajuste e conforto.

No total foram feitas três aplicações da primeira parte do instrumento padronizado BQUEST 2.0 com a participante, após cada visita para teste e uso do dispositivo, sendo que, a cada avaliação foram planejadas modificações nos protótipos, a partir de sua opinião e das notas atribuídas para cada quesito do dispositivo assistivo. A tabela 1 apresenta a pontuação das três entrevistas realizadas, bem como a média final de cada avaliação.

Tabela 1 - Resultados das três aplicações do B-QUEST

\begin{tabular}{|c|c|c|c|}
\hline $\begin{array}{l}\text { DISPOSITIVO DE TECNOLOGIA ASSISTIVA } \\
\text { Qual é seu grau de satisfação com: }\end{array}$ & Primeira aplicação* & Segunda aplicação* & Terceira aplicação* \\
\hline 1. Dimensões & 3 & 3 & 3 \\
\hline 2. Peso & 5 & 5 & 5 \\
\hline 3. Facilidade de Ajustar & 3 & 4 & 3 \\
\hline 4. Estabilidade e segurança & 3 & 4 & 5 \\
\hline 5. Durabilidade & 3 & 3 & 5 \\
\hline 6. Facilidade de uso & 2 & 4 & 2 \\
\hline 7. Conforto & 3 & 2 & 4 \\
\hline 8. Eficácia & 4 & 4 & 3 \\
\hline $\begin{array}{c}\text { SUBTOTAL } \\
\text { MÉDIA DE SATISFAÇÃO COM O RECURSO }\end{array}$ & 3,25 & 3,63 & 3,75 \\
\hline
\end{tabular}

* Escala - 1: Insatisfeito; 2: Pouco Satisfeito; 3: Mais ou menos satisfeito; 4: Bastante satisfeito; 5: Totalmente satisfeito Fonte: Elaborada pelos autores (2021). 
A partir do primeiro teste, a média aproximada de pontuação do instrumento de satisfação foi de três (mais ou menos satisfeito), sendo que a usuária expressou a necessidade de melhorias quanto ao ajuste do dispositivo na mão, estabilidade da escova e estética (cor do material). Diante disso, o layout do protótipo original foi repensado e uma nova proposta foi desenhada, conforme croqui e protótipo da Figura 6 ( $2^{\mathrm{a}}$ versão), cujas principais mudanças foram: tamanho da alça, que ficou menor do que a anterior (com uma diferença de dois centímetros), cor (alterada para preta) e encaixe, modificado para formato em " $X$ ", permitindo dois posicionamentos da escova (um para cada lado).

Figura 6 - Segundo protótipo desenvolvido, após aplicação do B-Quest (2.0)

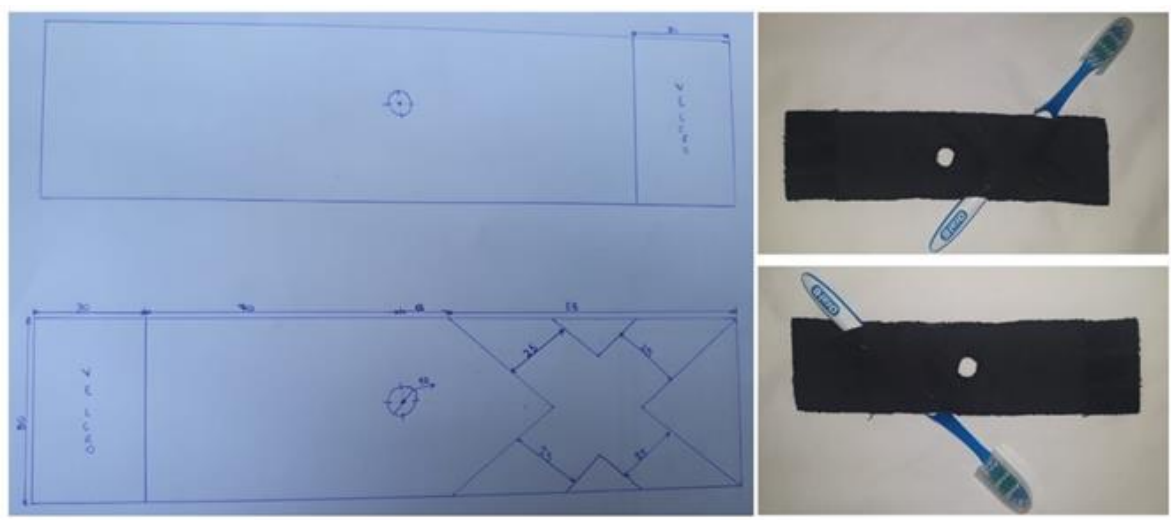

Fonte: Elaborada pelos autores (2021).

Ao testar a segunda versão do protótipo, feito sob medida e com mais ajustes, foi verificada melhor acomodação do dispositivo em sua mão (mais anatômico) e maior facilidade na colocação da escova e na execução da tarefa, comparando-se à situação inicial. Em um dos lados a dificuldade de escovação foi maior, porém ao longo do uso do dispositivo, isso se amenizou, identificando-se a necessidade de familiarização com o recurso e treino de uso. Um aspecto relatado pela usuária foi um leve desconforto com a costura do dispositivo.

Após analisar as pontuações da segunda aplicação do B-QUEST (Tabela 1), nota-se a atribuição de melhores notas em três itens: "facilidade de ajustar", "estabilidade e segurança" e "facilidade de uso", sendo um deles levantado como prioridade pela usuária. Com esta aplicação do teste, foi possível perceber a necessidade de se realizar um terceiro protótipo, com costura e acabamento mais delicados, como também adequar o posicionamento do encaixe para a escova, afastando-o do polegar. Surgiu também a ideia de se fazer um novo tipo de furo em formato oblongo e não em círculo, para maior conforto, 
http://dx.doi.org/10.5902/1984686X64660

criando-se um terceiro protótipo, também testado e avaliado pela participante. Este e os demais protótipos desenvolvidos encontram-se na Figura 7.

Figura 7 - Três protótipos funcionais desenvolvidos

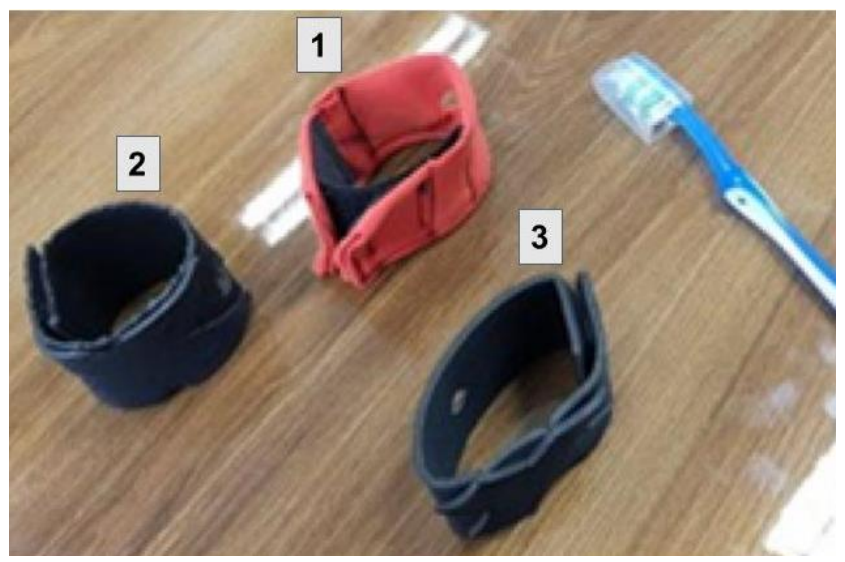

Fonte: Elaborado pelos autores (2021).

Ao longo do teste realizado com os três protótipos e analisando-se as pontuações obtidas nas aplicações do B-QUEST (Tabela 1), verifica-se que a diferença entre a primeira e a última média geral não é expressiva (de 3,25 para 3,63), porém se os itens forem analisados separadamente, nota-se melhora significativa em alguns deles, especialmente aqueles mencionados como passíveis de melhoria pela usuária. Dessa forma, na primeira aplicação tivemos uma pontuação maior do que 3 em apenas dois itens, sendo que na segunda aplicação tivemos pontuação acima de 3 em cinco itens, ou seja, em três itens houve uma mudança importante na pontuação: de 3 (Mais ou menos satisfeito) para 4 (Bastante satisfeito).

Ressalta-se que a comparação entre as pontuações do QUEST em três momentos diferentes se refere apenas às tentativas com dispositivos assistivos. Na etapa 1 (sem protótipo de dispositivo assistivo) ela não conseguiu executar a atividade e, portanto, mesmo que a satisfação ainda não seja total (pontuação 5), os recursos possibilitaram a execução da tarefa com independência e com algum grau de satisfação, que tenderá a aumentar na medida em que a usuária estiver familiarizada com o dispositivo.

\section{Discussão}

A maioria das pesquisas e projetos envolvendo o desenvolvimento de dispositivos de tecnologia assistiva não considera os aspectos socioculturais, que sofrem variação entre países desenvolvidos e em desenvolvimento (CHAVARRIAGA et al, 2014). Isso faz com 
http://dx.doi.org/10.5902/1984686X64660

que algumas soluções propostas sejam inviáveis, especialmente em países como o Brasil, em que o próprio contexto físico e social apresenta restrições ao processo de desenvolvimento. Ao contrário do que ocorre em países com maior atenção no desenvolvimento tecnológico para pessoas com deficiência, Maia e Freitas (2014) afirmam que o desenvolvimento de produtos assistivos no Brasil continua baseado na adaptação de objetos existentes ou na adoção de modelos de desenvolvimento incompletos, o que resulta na geração de produtos que nem sempre atendem efetivamente as demandas dos usuários. Contribuem ainda com esse quadro, a carência de pesquisas na área e a dificuldade de importação de produtos.

Embora existam metodologias de projeto e de desenvolvimento de produtos consolidadas na literatura (PAHL et al., 2007; ULLMAN, 2010; ULRICH; EPPINGER, 2015), fica evidenciada a necessidade de adaptação às características e especificidades do projeto de Tecnologia Assistiva para a obtenção de melhores resultados. Há uma lacuna ainda a ser preenchida nesta área, pois, embora existam alguns trabalhos relacionados, a ênfase dada ao processo de desenvolvimento em si é pequena (SANTOS; SILVEIRA, 2020).

Dessa forma, a metodologia "Projet8-TA" (SANTOS, 2020) proposta recentemente e utilizada neste trabalho, mostrou-se inovadora e concretiza a inserção dos usuários nas atividades iniciais do projeto, e também na avaliação iterativa dos protótipos conceituais e funcionais. Ela responde, de alguma forma, a demandas anteriormente relatadas por alguns autores, tais como Phillips e Zhao (1993), que afirmaram que o abandono dos dispositivos assistivos poderia ser reduzido através de um modelo colaborativo, com maior envolvimento dos consumidores no planejamento e nas tomadas de decisão. Poulson e Richardson (1998) acreditavam que métodos estruturados de projeto se fariam cada vez mais necessários, na medida em que o setor de Tecnologia Assistiva crescesse e se tornasse mais complexo.

Wu, Ma e Chang (2009) ressaltam que deve haver um delineamento da relação entre o usuário e o dispositivo a ser desenvolvido, para que o projeto seja o mais adequado possível. Nesse sentido, a metodologia aplicada mostrou-se eficiente na elaboração de protótipos funcionais, que foram refeitos a partir nas necessidades do usuário final, e tem potencial para sanar o que alguns autores verificam sobre os fatores de abandono de dispositivos de tecnologia assistiva, podendo evitar prejuízos do ponto de vista econômico, clínico e social. Dispositivos que não atendem as expectativas do usuário dificilmente serão 
http://dx.doi.org/10.5902/1984686X64660

incorporados à rotina, sendo que os fatores que levam ao abandono podem estar relacionados ao indivíduo, ao dispositivo e ao contexto (WESSELS et al, 2003).

Durante o processo de desenvolvimento do dispositivo para higiene oral, sobretudo na terceira fase, que consistiu na "Avaliação e Refinamento", a participante deste estudo pôde testar e avaliar os protótipos funcionais. O segundo e o terceiro protótipo foram elaborados a partir de sua participação e de suas considerações, em consonância com o que preconizam alguns profissionais e pesquisadores, que consideram fundamental 0 envolvimento direto do usuário e de seu contexto nesse processo, para que o recurso seja significativo e de fato venha a fazer parte da rotina do indivíduo (BERSCH, 2017; ROCHA; CASTIGLIONI, 2005). Segundo Ostuzzi et al. (2015), o usuário deve participar com suas ideias e criatividade, como um parceiro de desenvolvimento e não apenas como sujeito passivo, seguindo a linha de um conceito de coprojeto, que vai além de uma proposta centrada no cliente. Gherardini et al. (2018) afirmam que essa proposta de projeto participativo oferece uma resposta mais adequada às necessidades funcionais $e$ psicológicas de cada indivíduo, na medida em que este se envolve diretamente no processo e se vincula ao dispositivo assistivo, contribuindo para a diminuição da estigmatização do produto pelo próprio usuário e, por conseguinte, reduzindo os índices de abandono, em benefício do uso continuado.

Ficou evidente a satisfação da participante deste estudo em estar envolvida nas discussões sobre o dispositivo assistivo e interagir com a equipe na busca por soluções. Apesar de haver cada vez mais reconhecimento sobre a participação do usuário final no processo de desenvolvimento e implementação de Tecnologia Assistiva, alguns estudos, que também envolveram crianças e adolescentes com paralisia cerebral, mostraram que isso ainda não se tornou uma prática comum, havendo pouco ou nenhum envolvimento no processo de escolha de recursos (ALVES; MATSUKURA, 2011; KARLSSON; JOHNSTON; BARKER, 2016).

Há indicativos e relatos de pessoas com deficiência considerando que sua qualidade de vida sofre influência positiva da tecnologia assistiva, porém a sua satisfação precisa ser avaliada com critérios, o que levou ao desenvolvimento de ferramentas específicas para isso, dentre as quais se encontra o QUEST, utilizado neste estudo. O instrumento foi importante não apenas para identificar necessidades de melhoria nos protótipos funcionais, mas também para sistematizar a participação da adolescente no projeto, auxiliando-a no 
http://dx.doi.org/10.5902/1984686X64660

direcionamento de sua avaliação e dos aspectos a serem verificados no dispositivo, com possibilidade de quantificação.

De modo geral, a Tecnologia Assistiva tem sido considerada como um poderoso agente de mudança e sua satisfação está sendo cada vez mais valorizada (LAYTON et al, 2020), porém muitos dispositivos ainda são adquiridos com consideráveis problemas de usabilidade. Segundo Plos et al. (2012), o mercado nesta área é segmentado e, em geral, a competição se torna praticamente monopolística, gerando insatisfação e preço elevado. A escolha do usuário por uma marca ou produto se torna, algumas vezes, muito mais um balanço entre preço e serviço, do que efetivamente uma escolha em termos de vantagens e funcionalidades do produto.

Além disso, apesar da legislação brasileira apontar para o direito do cidadão com relação à concessão dos recursos de tecnologia assistiva, Bersch (2017) afirma que ainda é necessário muito trabalho para o reconhecimento e estruturação desta área no país, assim como incentivos à pesquisa e à produção nacional, em suas diversas aplicações e categorias, a fim de atender a demanda reprimida existente.

\section{Conclusões}

Faz-se necessário investir em financiamento, pesquisa e desenvolvimento no âmbito da saúde, particularmente da Tecnologia Assistiva, através de parceria intensiva com as diferentes especialidades da engenharia, de modo a se atender a demanda crescente e a proposta da política nacional para este setor. Objetiva-se, com isso, não somente a geração de produtos funcionais, que apresentem qualidade e inovação, mas também que sejam acessíveis e que propiciem ao usuário, tanto quanto possível, autonomia, autoestima, bemestar, independência e qualidade de vida.

A metodologia Projet8-TA mostrou-se eficiente e significativa para o desenvolvimento de dispositivos assistivos, na medida em que: 1) Incluiu profissionais da área da saúde nas três fases descritas; 2) Promoveu uma redução no tempo de desenvolvimento do projeto (tempo total de 4 meses) e gerou grau de inovação na solução conceitual; 3) Permitiu a equipe de projeto multidisciplinar desenvolver uma solução focada em um novo paradigma da manufatura, o projeto focado em customização; 4) Incluiu avaliação de satisfação dos protótipos funcionais por usuário final, com testes iterativos que levaram a novos protótipos.

A participação do usuário final, na terceira fase da metodologia, foi fundamental para o andamento do projeto e para que a versão final do dispositivo assistivo cumprisse a 
http://dx.doi.org/10.5902/1984686X64660

finalidade para a qual foi criado. A utilização do instrumento B-Quest (2.0) foi importante para quantificar a avaliação e opinião do indivíduo, bem como para identificar as melhorias necessárias nos protótipos funcionais, de acordo com as reais necessidades do usuário, possibilitando a criação de um recurso personalizado, na busca por melhor desempenho ocupacional na higiene oral, especificamente na escovação dos dentes, favorecendo a independência e reduzindo, consequentemente, as chances de abandono.

\section{Referências}

ALTSHULLER, Genrich Saulovich. Innovation Algorithm: TRIZ, systematic innovation and technical creativity. 2. ed. Translated and edited by Lev Shulyak and Steven Rodman. Worcester: Technical Innovation Center, 2007.

ALVES, Ana Cristina de Jesus; MATSUKURA, Thelma Simões. Percepção de alunos com paralisia cerebral sobre o uso de recursos de tecnologia assistiva na escola regular. Revista Brasileira de Educação Especial, Bauru, v.17(2), p.287-304, 2011. Disponível em: https://doi.org/10.1590/S1413-65382011000200008. Acesso em: 29 nov 2000.

ALVES, Ana Cristina de Jesus; MATSUKURA, Thelma Simões. O uso de recursos de tecnologia assistiva por crianças com deficiência física na escola regular: a percepção dos professores. Cadernos de Terapia Ocupacional da UFSCar, São Carlos, v.20, n.3, p.381392, 2012. Disponível em: http://dx.doi.org/10.4322/cto.2012.038. Acesso em: 29 nov 2000.

BARBOSA, Ismael Motta. Equipamentos de autoajuda: projeto e validação de um protótipo funcional para sustentação e movimentação de membros superiores. 2016. 191 p. Dissertação (Mestrado) - Escola de Engenharia de São Carlos, Universidade de São Paulo, São Carlos.

BERSH, Rita. Introdução à tecnologia assistiva. Porto Alegre, 2017, 20p. Disponível em: https://www.assistiva.com.br/Introducao_Tecnologia_Assistiva.pdf. Acesso em: 27 nov. 2020.

BOISSELLE, Angela K.; GRAJO, Lenin C. They Said: A Global Perspective on Access to Assistive Technology. The Open Journal of Occupational Therapy, v.6(3), Article 2, July 2018. Disponível em: https://doi.org/10.15453/2168-6408.1541. Acesso em: 27 nov. 2020.

BRACCIALLI, Lígia Maria Presumido. et al. Influência do assento da cadeira adaptada na execução de uma tarefa de manuseio. Revista Brasileira de Educação Especial [online]. v.14, n.1, p.141-154, 2008. Disponível em: ttp://dx.doi.org/10.1590/S141365382008000100011. Acesso em: 29 nov. 2020.

CARVALHO, Karla Emanuelle Cotias; GOIS JÚNIOR, Miburge Bolívar; SÁ, Katia Nunes. Tradução e validação do Quebec user evaluation of satisfaction with assistive technology (QUEST 2.0) para o idioma português do Brasil. Revista Brasileira de Reumatologia, v. 54, n. 4, p. 260-267, Aug 2014. Disponível em: http://dx.doi.org/10.1016/j.rbr.2014.04.003. Acesso em: 29 nov. 2020. 
CAVALCANTI, Alessandra. et al. Adaptive eating device: performance and satisfaction of a person with Parkinson's Disease. Canadian Journal of Occupational Therapy, v.87(3), p. 211-220, May 2020. Disponível em: https://doi.org/10.1177/0008417420925995. Acesso em: 29 nov. 2020.

CHAVARRIAGA, Ricardo; HURTADO, Maria N.; AGUILAR-ZAMBRANO, J.

Multidisciplinary design of suitable assistive technologies for motor disabilities in Colombia. In: IEEE GLOBAL HUMANITARIAN TECHNOLOGY CONFERENCE (GHTC 2014), San Jose, CA, p. 386-391, 2014. Disponível em: https://infoscience.epfl.ch/record/200117. Acesso em: 05 dez. 2020.

CHENG, Lin Chi; MELO FILHO, Leonel Del Rey. QFD - Planejamento da Qualidade. Editora Edgard Blücher. 568p., 2007.

CLAUSING, Don. Total quality development: a step-by-step guide to world-class concurrent engineering. New York: ASME Press, 1994. 506 p.

COOK, Albert M.; POLGAR, Janice Miller. Assistive Technologies: Principles and Practice. 3.ed. Maryland Heights: Mosby, 2008. 592 p.

COWAN, Donna. M.; KHAN, Yasmin. Assistive technology for children with complex disabilities. Current Paediatrics, v.15, n.3, p.207-212, jun 2005. Disponível em: https://doi.org/10.1016/j.cupe.2005.02.003. Acesso em: 01 dez. 2020.

DE COUVREUR, Lieven; GOOSSENS, Richard. Design for (every) one: co-creation as a bridge between universal design and rehabilitation engineering. CoDesign, v.7, n.2, p.107-121, 2011. Disponível em: https://doi.org/10.1080/15710882.2011.609890. Acesso em: 01 dez. 2020.

DEMERS, Louise; WEISS-LAMBROU, Rhoda; SKA, B. The Quebec User Evaluation of Satisfaction with Assistive Technology (QUEST 2.0): an overview and recent progress. Technology and Disability, v.14, n.3, p.101-105, 2002.

DIETRICH, Ursula. Toothbrush with curved handle, United States Patent. 4109339, 1977, 5p. Disponível em: https://patents.google.com/patent/US4351080A/en. Acesso em: $01 \mathrm{dez} .2020$.

GELÁNYI, László. Active hand orthosis, WO 2018/138537 A1, 2018, 30p. Disponível em: https://patentscope.wipo.int/search/en/detail.jsf?docld=WO2018138537. Acesso em: 25 nov. 2020.

GHERARDINI, Francesco. et al. A co-design method for the additive manufacturing of customized assistive devices for hand pathologies. Journal of Integrated Design and Process Science, v.22, n.1, p. 21-37, 2018. Disponível em: http://doi: 10.3233/jid-20180002. Acesso em: 03 dez. 2020.

GRAY, David B.; COOK, Albert M. Assistive technology. Encycloaedia Britannica, May 2017. Disponível em https://www.britannica.com/science/assistive-technology. Acesso em 05 dez. 2020. 
HIRATUKA, Erika; MATSUKYRA, Thelma; PFEIFER, Luzia lara. Adaptação transcultural para o Brasil do sistema de classificação da função motora grossa (GMFCS). Revista Brasileira de Fisioterapia, São Carlos, v.14, n.6, p.537-44, nov./dez. 2010. Disponível em: https://doi.org/10.1590/S1413-35552010000600013. Acesso em: 01 dez. 2020.

$\mathrm{HU}$, Jack S. Evolving paradigms of manufacturing: from mass production to mass customization and personalization. Procedia CIRP, v.7, p.3-8, 2013.

ITS Brasil - Instituto de Tecnologia Social. Tecnologia Assistiva nas Escolas Recursos básicos de acessibilidade sócio-digital para pessoas com deficiência. Ministério da Ciência e Tecnologia, Brasil, 2008. Disponível em: https://docs.wixstatic.com/ugd/85fd89_1484aef95a4544debaa6cdb8343b678b.pdf . Acesso em: 25 nov. 2020.

KANEKO, Paula M. Desenvolvimento de solução construtiva e mock-up de uma órtese infantil de mão e punho para auxílio em atividades diárias. 89 p. Qualificação (Mestrado em Engenharia Mecânica) - Escola de Engenharia de São Carlos, Universidade de São Paulo, São Carlos, 2018.

KARLSSON, Petra; JOHNSTON, Christine; BARKER, Katrina. Achieving classroom goals using assistive technology: perspectives from students with cerebral palsy and their parentes. Developmental Medicine \& Child Neurology, v.58, p.94-95, September 2016. Disponível em: https://doi.org/10.1111/dmcn.22_13225. Acesso em: 01 dez. 2020.

LAYTON, Natasha. et al. Opening the GATE: systems thinking from the global assistive technology aliance. Disability and Rehabilitation: Assistive Technology, v.15(5), p. 484-490, Apr 2020. Disponível em: https://doi.org/10.1080/17483107.2020.1738565. Acesso em: 25 nov. 2020.

LINO, Thaís Breternitz. et al. Efeitos do Uso de Recursos de Tecnologia Assistiva para Promover Independência em Atividades de Vida Diária para uma Criança com Paralisia Cerebral. Revista Brasileira de Educação Especial, Bauru, v.26, n.1, p.35-50, Jan.Mar., 2020.

LOUREIRO, Isabela Morcelli. Projeto e desenvolvimento do protótipo funcional de um prato de alimentação adaptado para pessoas com distúrbios neuromotores e tremor essencial. 2019. 102 p. Trabalho de Conclusão de Curso (Engenharia de Materiais e Manufatura), Escola de Engenharia de São Carlos, Universidade de São Paulo, São Carlos.

MAIA, Fernanda do Nascimento; FREITAS, Sidney Fernandes. Proposta de um fluxograma para o processo de desenvolvimento de produtos de Tecnologia Assistiva. Cadernos de Terapia Ocupacional da UFSCar, v.22, n.3, 2014. Disponível em: https://doi.org/10.4322/cto.2014.078 Acesso em: 30 nov 2020.

MANZINI, Mariana Gurian; ASSIS, Carolina Penteado; MARTINEZ, Claudia Maria Simões. Contribuições da Terapia Ocupacional na área da comunicação suplementar e/ou alternativa. Cadernos Brasileiros de Terapia Ocupacional da UFSCar, São Carlos, v.21, n.1, p.59-73, 2013. 
MARTINEZ, Barbara dos Santos. Projeto e avaliação de satisfação de um dispositivo assistivo universal, para auxiliar atividades terapêuticas com pintura. 2020. 142 p. Trabalho de Conclusão de Curso (Engenharia de Materiais e Manufatura), Escola de Engenharia de São Carlos, Universidade de São Paulo, São Carlos.

OLIVEIRA, Franciane Teixeira de; BRACCIALLI, Lígia Maria Presumido. Influência do mobiliário nas atividades lúdicas em escolares com paralisia cerebral. Revista Brasileira de Crescimento e Desenvolvimento Humano, São Paulo, v.18, n.3, p.308320, dez. 2008.

OMS - Organização Mundial da Saúde. CIF: Classificação Internacional de Funcionalidade, Incapacidade e Saúde. Centro colaborador da OMS para a Classificação de Doenças em português/USP, Editora da Universidade de São Paulo: São Paulo, 2003.

OMS - Organização Mundial da Saúde. Global Cooperation on Assistive Technology About us. Disponível em:

https://www.who.int/phi/implementation/assistive_technology/phi_gate/en/The GATE initiative, 2017. Acesso em: 30 nov 2020.

OSTENSJO, Sigrid; CARLBERG, Eva Brogren; VOLLESTAD, Nina K. The use and impact of assistive devices and other environmental modifications on everyday activities and care in young children with cerebral palsy. Disability and Rehabilitation, v.27, n.14, p.849861, jul 2005. Disponível em: https://doi.org/10.1080/09638280400018619. Acesso em: 30 nov 2020.

OSTUZZI, Francesca. et al. + TUO project: low cost 3D printers as helpful tool for small communities with rheumatic diseases. Rapid Prototyping Journal, v.21, n.5, p.491-505, 2015.

PAHL, Gerhard. et al. Engineering Design: A Systematic Approach. Springer Science \& Business Media, 2007.

PALISANO, Robert. Development and reliability of a system to classify gross motor function in children with cerebral palsy. Developmental Medicine and Child Neurology. v.39, n.4, p.214-23, Apr 1997. Disponível em: https://doi.org/10.1111/j.14698749.1997.tb07414.x. Acesso em: 30 nov 2020.

PELOSI, Miryam Bonadiu; NUNES, Leila Regina d'Oliveira de Paula. Caracterização dos professores itinerantes, suas ações na área de tecnologia assistiva e seu papel como agentes de inclusão escolar. Revista Brasileira de Educação Especial [online], v.15, n.1, p.141-154, 2009. Disponível em: http://dx.doi.org/10.1590/S141365382009000100010 Acesso em: 30 nov 2020.

PLAK-VAC, Oral Suction Evacuator Brush. Disponível em: https://www.medline.com/product/Plak-Vac-Oral-Brush-Evacuators-by-TrademarkCorp/Z05-PF38799. Acesso em: 16 jul. 2020.

PLOS, Ornella. et al. A universalist strategy for the design of assistive technology. International Journal of Industrial Ergonomics, v.42, n.6, p.533-541, 2012. 
PORTNOVA, Alexandra A. et al. Design of a 3D-printed, open-source wrist-driven orthosis for individuals with spinal cord injury. PloS one, v. 13, n. 2, p. e0193106, 2018. Disponível em:

https://journals.plos.org/plosone/article?id=10.1371/journal.pone.0193106. Acesso em: 16 jul. 2020.

PHILLIPS, Betsy; ZHAO, Hongxin. Predictors of assistive technology abandonment. Assistive technology, v. 5, n. 1, p. 36-45, 1993. Disponível em:

https://doi.org/10.1080/10400435.1993.10132205. Acesso em: 06 dez. 2020.

POULSON, David; RICHARDSON, Simon. USERfit-a framework for user centred design in assistive technology. Technology and Disability, v. 9, n. 3, p. 163-171, 1998.

RIEMER-REISS, Marti L.; WACKER, R. R. Factors associated with assistive technology discontinuance among individuals with disabilities. Journal of Rehabilitation, v.66, n.3, p.44-50, 2000.

ROCHA, Aila Narene Dahwache Criado; DELIBERATO, Débora. Tecnologia assistiva para a criança com paralisia cerebral na escola: identificação das necessidades.

Revista Brasileira de Educação Especial [online], v.18 (1), p. 71-92, 2012. Disponível em: https://doi.org/10.1590/S1413-65382012000100006 Acesso em: 06 dez 2020.

ROCHA, Eucenir Fredini; CASTIGLIONI, Maria do Carlo. Reflexões sobre recursos tecnológicos: ajudas técnicas, tecnologia assistiva, tecnologia de assistência e tecnologia de apoio. Revista de Terapia Ocupacional da USP, São Paulo, v.16, n.3, p.97-104, 2005. Disponível em: https://doi.org/10.11606/issn.2238-6149.v16i3p97-104 Acesso em: 30 nov 2020.

SANTOS, Artur Valadares de Freitas. Proposta de metodologia, da perspectiva da engenharia, para o projeto de dispositivos assistivos com abordagem centrada no usuário e o auxílio da manufatura aditiva, no contexto da Tecnologia Assistiva . 2020. 316 p. Tese (Doutorado em Engenharia Mecânica), Escola de Engenharia de São Carlos, Universidade de São Paulo, São Carlos.

SANTOS, Artur Valadares de Freitas; SILVEIRA, Zilda. C. T-d8sign: methodology to support development of assistive devices focused on user-centered design and $3 \mathrm{D}$ technologies". Journal of the Brazilian Society of Mechanical Sciences and Engineering. 2020. Disponível em: https://link.springer.com/article/10.1007/s40430-02002347-w Acesso em: 30 nov 2020.

SANTOS, Artur Valadares de Freitas. et al. User-centered design of a customized assistive device to support feeding. In: CIRP DESIGN, 29th, 2019. Procedia CIRP: Elsevier, v.84, p.743-748. Disponível em: https://doi.org/10.1016/j.procir.2019.04.318 Acesso em: 30 nov 2020.

SILVA, Ana Isabel T. et al. Perfil funcional de crianças com paralisia cerebral na escola regular segundo tipo de escola e comprometimento motor. Temas sobre desenvolvimento, São Paulo, v.13, n.74, p. 5-13, 2004. 
SOUZA, Alessandra Cavalcanti de Albuquerque. Avaliação dos dispositivos destinados ao uso de sustentação e movimentação de membros superiores e proposta da melhoria do projeto baseada na integração QFD e Análise Funcional, 2016. 178 f. Tese (Doutorado) - Programa de Pós-Graduação Interunidades em Bioengenharia - EESC/FMRP/IQSC, Universidade de São Paulo, São Carlos.

SMITH, Roger O. et al. Assistive technology products: a position paper from the first global research, innovation, and education on assistive technology (GREAT) summit. Disability and Rehabilitation: Assistive Technology, v.13(5), p.473-485, Jul 2018. Disponível em: https://doi.org/10.1080/17483107.2018.1473895 Acesso em: 25 nov 2020.

SQUIRES, Luke A.; WILLIAMS, Nefyn; MORRISON, Val L. Matching and accepting assistive technology in multiple sclerosis: A focus group study with people with multiple sclerosis, carers and occupational therapists. Journal of Health Psychology, v.24(4), p. 480-494, Mar 2019. Disponível em: https://doi.org/10.1177/1359105316677293 Acesso em: 30 nov 2020.

SUNG-SHAN, Peng. Toothbrush, US. Pat. 4429434, 1984, 6p. Disponível em: https://patents.google.com/patent/CN102356944B/en Acesso em: 30 nov 2020.

ULLMAN, David G. The mechanical design process. 4th ed. New York: McGraw-Hill, 2010.

ULRICH, Karl T.; EPPINGER, Steve D. Product design and development. 6th ed. New York: McGraw-Hill Education, 2015.

WESSELS, R. et al. Non-use of provided assistive technology devices, a literature overview. Technology and Disability, v. 15, n. 4, p. 231-238, 2003.

WU, F. G.; MA, M. Y.; CHANG, R. H. A new user-centered design approach: a hair washing assistive device design for users with shoulder mobility restriction. Applied Ergonomics, v. 40, n. 5, p. 878-886, 2009.

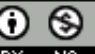

This work is licensed under a Creative Commons Attribution-NonCommercial 4.0 International (CC BY-NC 4.0) 